\title{
Stimulus similarity and positive induction
}

\author{
JAMES S. MacDONALL and HENRY MARCUCELLA \\ Boston University, Boston, Massachusetts 02215
}

\begin{abstract}
In order to assess the effect of stimulus similarity on the magnitude of positive induction, the keypeck responses of two pigeons were reinforced in the presence of one of three line orientations on a three-ply multiple schedule with identical variable-interval 2-min schedules of reinforcement associated with each component. The constant-component and variablecomponent stimuli remained unchanged. The altered-component stimulus was systematically varied to increase or decrease its similarity to the variable-component stimulus, while the variable-component reinforcement schedule was periodically changed to a differentialreinforcement-of-high-rate schedule. Positive induction occurred in six out of eight conditions, and the magnitude of the positive induction was a direct function of stimulus similarity. These results are not accounted for by Terrace's (1966) interpretation of multiple-schedule interactions.
\end{abstract}

Hemmes and Eckerman (1972) demonstrated that response-rate increases in both components of a multiple schedule (positive induction) occurred when a differential-reinforcement-of-high-rate (DRH) contingency was added to one component (variable) of the schedule. The rate increase in the unchanged component (constant) could be considered as an example of betweencomponent generalization of high rates of responding. Alternatively, Hemmes and Eckerman suggested that their results could be accounted for by Terrace's (1963a, $1963 \mathrm{~b}, 1966)$ theory of positive contrast. According to Terrace, the various schedule changes in the variable component (e.g., extinction, blackout, and punishment) which produce rate increases in the constant component have a common element: the introduction of aversive by-products generated by such schedule changes. If the introduction of a DRH schedule also generates aversive by-products, as suggested by Fantino (1968), then the increased constant-component rate reported by Hemmes and Eckerman (1972) may be the result of the introduction of these by-products and independent of the rate increases occurring in the variable component.

One test of this extension of Terrace's position to situations expected to produce positive induction would be to examine the effect of stimulus similarity on the magnitude of positive induction. If aversive by-products are related to the development of positive induction, then rate changes in the constant component would be

Preparation of this manuscript was supported in part by the Washingtonian Center for Addictions. Portions of this paper were presented at the convention of the Eastern Psychological Association in New York in 1975. The authors wish to thank Sara Knuth and Michael Levy for their help in data collection. Reprints may be obtained from either James S. MacDonall, Department of Psychology, Fordham University, Bronx, New York 10458, or Henry Marcucella, Department of Psychology, Boston University, 64 Cummington Street, Boston, Massachusetts 02215. inversely related to the similarity among the variableand constant-component stimuli. For example, in a three-component multiple schedule, a schedule change with aversive by-products in the variable component should result in greater response-rate increases in the component whose stimuli are least similar to the variablecomponent stimuli.

The present experiment examined the relationship between stimulus similarity and the magnitude of positive induction within a three-component multiple schedule. One component was periodically correlated with a DRH schedule (variable component), one was unchanged throughout training (constant component), and in one component the stimulus was periodically changed (altered component).

\section{METHOD}

\section{Subjects}

Two male naive White Carneaux pigeons were maintained at $80 \%$ of their free-feeding weight throughout the experiment. Water was available only in the home cage.

\footnotetext{
Apparatus

The apparatus was a standard pigeon test chamber (Gerbrands Model G5610) containing two clear response keys and enclosed in a sound-attenuating chamber. Only the left key, transilluminated by an Industrial Electronics Engineer in-line projector, was used. The left key was transilluminated such that a dark line $.3 \times 1.5 \mathrm{~cm}$ appeared on a light background at any of five orientations: 0 (vertical), $15,45,75$, and 90 deg clockwise from vertical. Pecks of at least $.15 \mathrm{~N}$ on the key were recorded and operated a feedback relay. The reinforcer was $3.4 \mathrm{sec}$ access to mixed grain delivered by a food hopper located below and between the two keys. During the reinforcement cycle the keylight was turned off and two 4.75-W lamps illuminated the food hopper. The houselight remained off during the session. Masking noise was provided by a white-noise generator and an exhaust fan. Electromechanical programming equipment that controlled the presentation of stimuli and the recording of responses was located in an adjacent room.
} 
Table 1

Sequence of Conditions and Number of Sessions in Each Condition for Each Pigeon

\begin{tabular}{|c|c|c|c|c|c|}
\hline \multirow[b]{2}{*}{$\begin{array}{c}\text { Condi- } \\
\text { tion }\end{array}$} & \multirow[b]{2}{*}{ Stimuli } & \multicolumn{2}{|l|}{ Pigeon 760} & \multicolumn{2}{|c|}{ Pigeon 2442} \\
\hline & & Schedule & $\begin{array}{l}\text { Ses- } \\
\text { sions }\end{array}$ & Schedule & $\begin{array}{r}\text { Ses- } \\
\text { sions }\end{array}$ \\
\hline 1 & $0,15,90$ & VI VI VI & 20 & VI VI VI & 16 \\
\hline 2 & $0,15,90$ & VI VI VIDRH & 17 & VIDRH VI VI & I 25 \\
\hline 3 & $0,15,90$ & VI VI VI & 11 & VI VI VI & 16 \\
\hline 4 & $0,45,90$ & VI VI VI & 5 & VI VI VI & 5 \\
\hline 5 & $0,45,90$ & VI VI VIDRH & 27 & VIDRH VI VI & I 25 \\
\hline 6 & $0,45,90$ & VI VI VI & 11 & VI VI VI & 33 \\
\hline 7 & $0,75,90$ & VI VI VI & 8 & VI VI VI & 33 \\
\hline 8 & $0,75,90$ & VI VI VIDRH & 24 & VIDRH VI VI & I 31 \\
\hline 9 & $0,75,90$ & VI VI VI & 18 & VI VI VI & 19 \\
\hline 10 & $0,15,90$ & VI VI VI & 5 & VI VI VI & 10 \\
\hline 11 & $0,15,90$ & VI VI VIDRH & 10 & VIDRH VI VI & I 14 \\
\hline 12 & $0,15,90$ & VI VI VI & 9 & VI VI VI & 61 \\
\hline
\end{tabular}

\section{Procedure}

Keypecks were reinforced in the presence of one of three orientations on a three-ply multiple schedule with identical constant-probability variable-interval (VI) 2-min schedules associated with each component. The values of the 20 intervals were derived from Catania and Reynolds (1968). A daily 2-h session consisted of $202-\mathrm{min}$ presentations of each line orientation. Orientations were presented no more than twice in succession, and each orientation directly followed the preceding one without any intervening timeout or blackout. Preliminary data suggested that brightness easily acquired control over the pigeons' keypecking. Thus, the brightness of each stimulus was changed at the beginning of each component by placing one of $11 \mathrm{re}$ sistors, ranging from 0 to $33 \mathrm{ohms}$ in 3.3 -ohm steps, in series with the keylight. The line-tilt stimuli and brightness were not correlated.

In the constant component, both the stimulus (either 0 or $90 \mathrm{deg}$ ) and the reinforcement schedule remained the same throughout the experiment. In the variable component, the reinforcement schedule was periodically changed to VI DRH but the stimulus (either 90 or $0 \mathrm{deg}$ ) remained the same throughout the experiment. In the altered component, the stimulus $(15,45$, or $75 \mathrm{deg}$ ) was changed but the reinforcement schedule remained the same throughout the experiment. The sequence of schedules, correlated stimuli, and number of sessions in each condition are summarized in Table 1.

\section{DRH}

During four conditions for each pigeon, the reinforcement schedule associated with the variable component was changed to a VI 105-sec DRH. The DRH was in effect when the VI schedule had time-out. Schedule changes were made only after response rates were stable for 5 days or after the response rate in the DRH component had reached a peak and was decreasing. The DRH was programmed by wiring a capacitor, resistor (R1), and relay in parallel and a resistor (R2) in series with this circuit (Ferster \& Skinner, 1957, p. 33). In general, increasing the resistance of $\mathrm{R} 2$ or decreasing the resistance of $\mathrm{R} 1$ increased the minimum rate required for reinforcement; increasing the capacitance of the capacitor increased the number of responses required, at a particular response rate, for reinforcement to occur. The parameters of the circuit were selected daily in order to increase the response rate and maintain the reinforcement frequency.

The VI DRH program could decrease the variable-component reinforcement frequency when a sequence of several responses was required for reinforcement. To prevent this decrease, which could lead to rate increases in the altered and constant com- ponents (Reynolds, 1961), the VI 120 -sec schedule was changed to a VI 105-sec schedule, which produced a maximum of 23 instead of 20 reinforcers per session.

\section{RESULTS AND DISCUSSION}

Figure 1 presents the response rate as a function of the stimuli during Conditions 2, 5, 8, and 11. Presented on the far right are the ranges of the mean rates for the last five-baseline sessions for the three components in each condition. Since we were interested in examining the effect of stimulus similarity, we focused on those sessions in which stimulus similarity was most likely to have an effect, that is, the sessions in which the highest

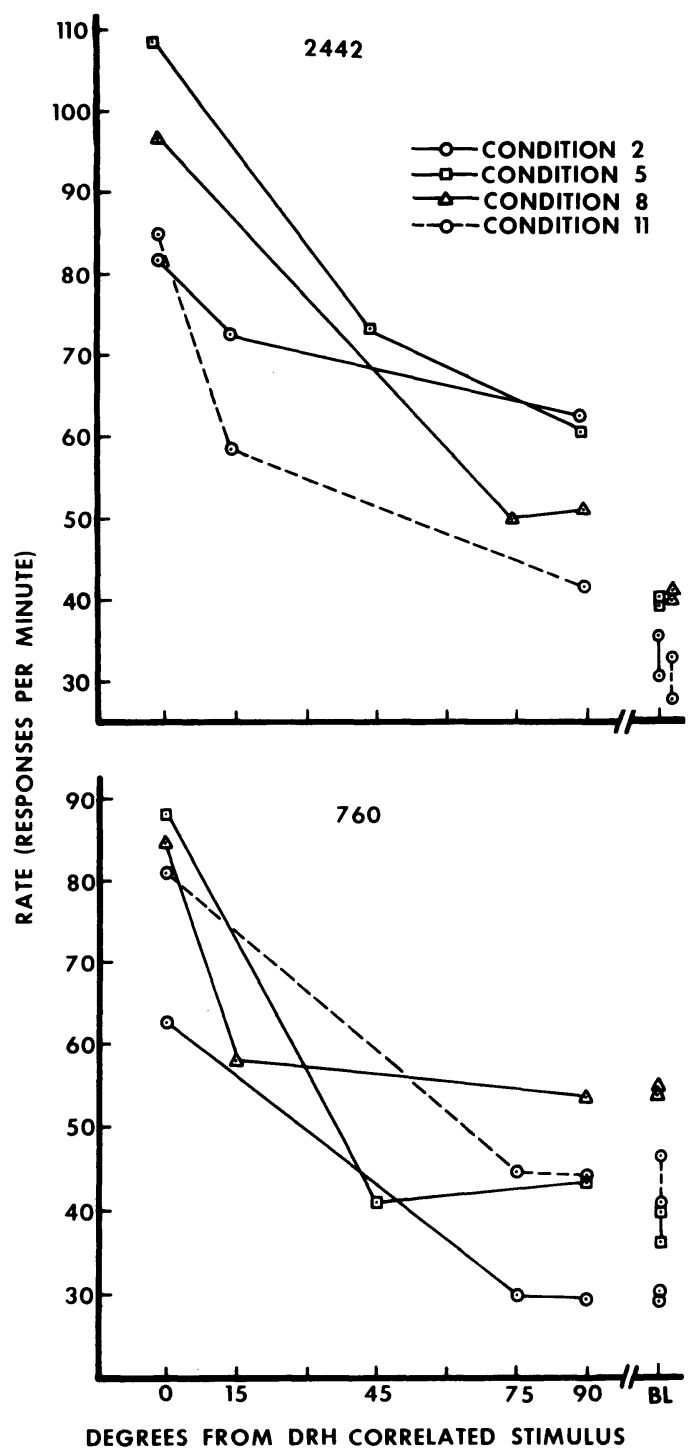

Figure 1. Response rates for each component for both pigeons during the five consecutive sessions that produced the highest response rate in the variable component. At the far right are the range of mean component rates during the last five sessions of baseline for each condition. 


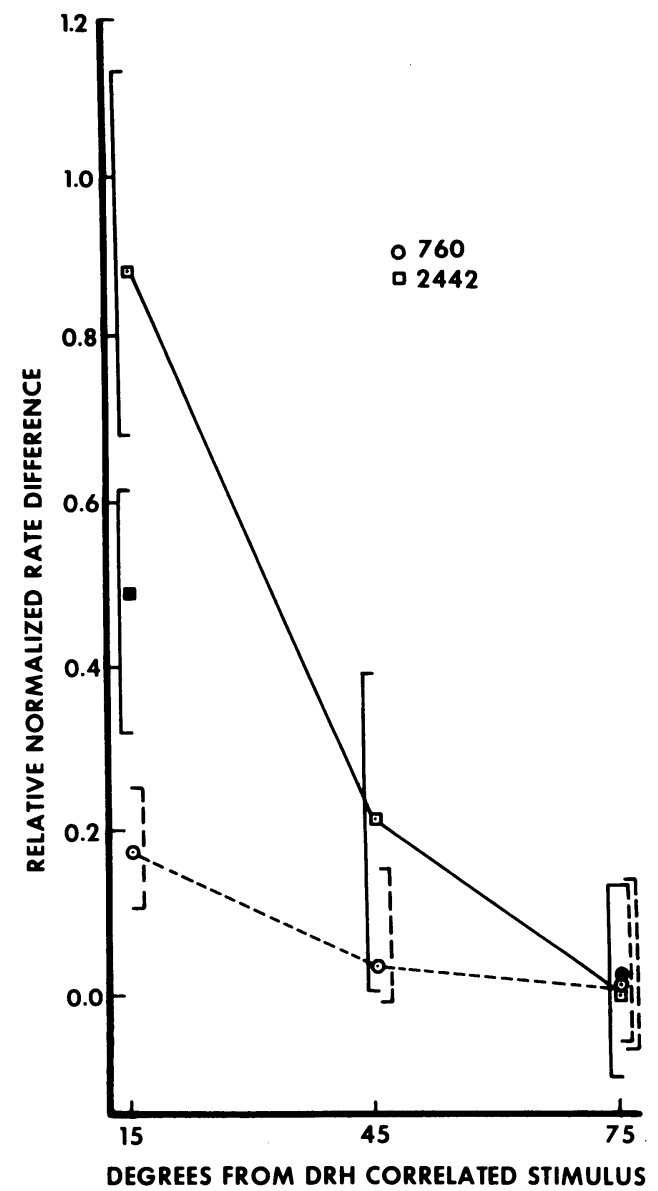

Figure 2. Relative normalized rate changes for the altered component as a function of the similarity among the alteredand variable-component stimuli for both pigeons. The filled circle and square represent data obtained during the replication (Condition 11). Vertical lines represent range of the scores from which the means were obtained.

DRH rate occurred. The five consecutive sessions that produced the highest mean variable-component rates for each of the four DRH conditions for each pigeon are presented in Figure 1. In all four conditions for 2442, and in Conditions 5 and 8 for 760 , positive induction was observed. The highest rate occurred in the variable component, while the rates in all three components increased.

An index of the relative rate change in the altered component was obtained by comparing the magnitude of the altered-component rate increase to the magnitude of the variable-component rate increase. Figure 2 shows the relative normalized-rate ratio as a function of the difference between the variable- and altered-component stimuli. The relative normalized-rate ratio was obtained by first determining the five consecutive sessions that produced the highest variable-component mean rate. Then the component rates obtained during those five sessions were normalized by dividing the daily session rate in each component by each component's median rate obtained in the last five baseline sessions. Normalized-component rates were used for comparisons between conditions because of difference (a) in rates during baseline and (b) in the maximum rate produced by the DRH schedule. The relative normalized-rate ratio (R) was calculated according to the formula

$$
R=(A-C) /(V-C),
$$

where $\mathbf{A}$ is the mean normalized altered-component rate, $\mathrm{C}$ is the mean normalized constant-component rate, and $\mathrm{V}$ is the mean normalized variable-component rate. Open circles represent the data of Pigeon 760 and open squares the data of Pigeon 2442. The filled circle and square represent data obtained during replication (Condition 11). Vertical solid or dashed lines represent the range of scores for the five sessions used to obtain relative normalized-rate ratios. Although more pronounced for 2442 than for 760 , it is clear from Figure 2 that, as the similarity among the altered-and variable-component stimuli increased, the alteredcomponent rate approached the variable-component rate.

Table 2 presents, for each bird, the total frequency of reinforcement per component for the five sessions of each condition that are presented in Figures 1 and 2 . Both birds received a total of approximately 100 reinforcers per component, with no systematic differences in the frequency of reinforcement across conditions.

The present data replicate the results obtained by Hemmes and Eckerman (1972); that is, positive induction occurred in six out of eight occasions (Figure 1). However, the present results do not support the suggestion by Hemmes and Eckerman (1972) that positive induction was a function of the aversive by-products of the variable-component schedule. The present results showed that there was a direct relationship between the relative rate increase in the altered component and the similarity among the variable- and altered-component stimuli (Figure 2). If aversive by-products generated by the introduction of DRH schedules was a factor in producing positive induction, then an inverse relationship should have been obtained.

The present results are consistent with the alternative interpretation of positive induction, that rate increases

Table 2

Obtained Relative Reinforcement Frequency in Each Component During the Five Sessions in Which the Highest Mean Variable-Component Rate Occurred

\begin{tabular}{|c|c|c|c|c|c|c|c|c|}
\hline & \multicolumn{4}{|c|}{ Pigeon 2442} & \multicolumn{4}{|c|}{ Pigeon 760} \\
\hline & \multicolumn{4}{|c|}{ Condition } & \multicolumn{4}{|c|}{ Condition } \\
\hline & 2 & 5 & 8 & 11 & 2 & 5 & 8 & 11 \\
\hline Variable & .35 & .34 & .34 & .34 & .34 & .36 & .32 & .35 \\
\hline Altered & .32 & .33 & .33 & .32 & .34 & .35 & .34 & .32 \\
\hline Constant & .33 & .33 & .33 & .33 & .32 & .29 & .34 & .33 \\
\hline N & 314 & 304 & 295 & 305 & 297 & 283 & 282 & 300 \\
\hline
\end{tabular}


in the unchanged components result from the induction of the pattern of responding generated in the variable component. First, the magnitude of the change in the relative response rates in the altered component was directly related to the degree of similarity among the altered- and variable-component stimuli (Figure 2). For 2442 the effect was clear, while for 760 the effect was seen only when the altered-component stimulus differed from the variable-component stimulus by $15 \mathrm{deg}$. Second, when response rates were plotted as a function of stimulus value, eight orderly generalization gradients were obtained (Figure 1). Third, the similarities and differences among the functions produced in Figure 1 for each pigeon reflected differences in training history. Such differences are often reported in the stimulus control literature (Lawrence, 1952; Ray, 1967; Schlosberg \& Solomon, 1943) and suggest the involvement of similar processes. For example, Ray (1967) showed that beginning training with an easy discrimination and progressively increasing the difficulty of the discrimination produced greater stimulus control than did beginning training with the difficult discrimination. In the present experiment 760 was initially presented with an easy discrimination that was progressively made more difficult. That is, the discriminative stimuli in the variable and altered components were initially dissimilar and similarity was increased over sessions. The converse was true for 2442 . These differences in training history were reflected in the differences in the degree of stimulus control. The slope of the gradient between the 0 - and 15-deg stimuli was steeper for 760 (Figure 1, Condition 8) than for 2442 (Figure 1, Condition 2). Similar effects were evident when the slopes of the gradients between the 0-and 45-deg stimuli were compared.

\section{REFERENCES}

Catania, A. C., \& Reynolds, G. S. A quantitative analysis of the responding maintained by interval schedules of reinforcement. Journal of the Experimental Analysis of Behavior, 1968, 11, 327-383.

Fantivo, E. Effects of required rates of responding upon choice. Journal of the Experimental Analysis of Behavior, 1968, 11, 15-22.

Ferster, C. B., \& Skinner, B. F. Schedules of reinforcement. New York: Appleton-Century-Crofts, 1957.

Hemmes, N. S., \& Eckerman, D. A. Positive interaction (induction) in multiple variable interval, differential reinforcement of high rate schedules. Journal of the Experimental Analysis of Behavior, 1972, 17, 51-57.

LAWRENCE, D. H. The transfer of a discrimination along a continuum. Journal of Experimental Psychology, 1952, 44, 511-516.

RAY, B. A. The course of acquisition of a line-tilt discrimination by rhesus monkeys. Journal of the Experimental Analysis of Behavior, 1967, 10, 17-23.

REYNoLDS, G. S. Behavioral contrast. Journal of the Experimental Analysis of Behavior, 1961, 4, 57-71.

SchlosBerg, H., \& Solomon, R. Latency of response in a choice discrimination. Journal of Experimental Psychology, 1943, 33, 22-39.

TERRACE, H. S. Discrimination learning with and without "errors." Journal of the Experimental Analysis of Behavior, $1963,6,1-27$. (a)

Terrace, H. S. Errorless transfer of a discrimination across two continua. Journal of the Experimental Analysis of Behavior, 1963, 6. 223-232. (b)

TERRACE, H. S. Stimulus control. In W. K. Honig (Ed.), Operant behavior: Areas of research and application. New York: Appleton-Century-Crofts, 1966.

(Received for publication March 20, 1978.) 